\title{
Lung transplantation and survival outcomes in patients with oxygen-dependent COPD with regard to their alpha-I antitrypsin deficiency status
}

\section{Magnus Ekström \\ Hanan Tanash}

Department of Respiratory Medicine and Allergology, Skåne University Hospital, Lund University, Lund, Sweden
Correspondence: Hanan Tanash Department of Respiratory Medicine and Allergology, Skåne University Hospital, Jan Waldenströms gata 24, S-205 02 Malmö, Sweden

Email hanan.tanash@med.lu.se
This article was published in the following Dove Press journal:

International Journal of COPD

7 November 2017

Number of times this article has been viewed

Background: Individuals with severe alpha-1 antitrypsin deficiency (AATD) have an increased risk of developing COPD. However, outcomes during long-term oxygen therapy (LTOT) in patients with severe AATD and hypoxemia are unknown.

Patients and methods: This was a prospective, population-based, consecutive cohort study of patients on LTOT due to COPD in the period from January 1, 1987, to June 30, 2015, in the Swedish National Registry for Respiratory Failure (Swedevox). Severe AATD was identified using the Swedish AATD registry and confirmed by isoelectric focusing. Data on lung transplantation (LTx) were obtained from the two lung transplantation centers in Sweden. Mortality and causes of death were assessed based on the National Causes of Death Registry and analyzed using multivariable Cox regression.

Results: A total of 14,644 patients who started LTOT due to COPD were included in this study. No patient was lost to follow up. Patients with AATD were younger, included more males and more never smokers, and had fewer comorbidities. During a median follow-up of 1.6 years (interquartile range [IQR], 2.7) on LTOT, patients without severe AATD had a higher mortality, hazard ratio [HR] 1.53 (95\% CI, 1.24-1.88), adjusting for age, sex, smoking status, body mass index, performance status, level of hypoxemia, and comorbidities. Cardiovascular deaths were increased. A higher proportion of AATD patients underwent LTx, 53 (19\%) vs 118 (1\%). Survival after LTx was similar for AATD and non-AATD patients and was predicted by age.

Conclusion: In oxygen-dependent COPD, patients with severe AATD have a longer survival time on LTOT, but they have a similar prognosis after lung transplantation compared with patients without AATD.

Keywords: COPD, long-term oxygen therapy, lung transplantation, severe alpha-1 antitrypsin deficiency, survival

\section{Introduction}

Severe alpha-1 antitrypsin deficiency (AATD) is a common genetic condition, defined by the presence of the PiZZ phenotype that predisposes to COPD. PiZZ is present in $1 \%-2 \%$ of COPD patients. ${ }^{1}$ The treatment of COPD patients due to severe AATD includes the usual COPD therapies, such as vaccinations, bronchodilators, rehabilitation, and surgical interventions in selected patients, and long-term oxygen therapy (LTOT) in patients with severe chronic hypoxemia. ${ }^{2}$ For patients with severe AATD, alpha-1 antitrypsin augmentation therapy is not generally recommended in Sweden.

Patients with severe AATD have a shorter survival time than the general population matched for smoking habits, with increased mortality in particular due to 
hepatobiliary disease and early-onset emphysema, especially in smokers. ${ }^{3}$ After lung transplantation (LTx), AATD patients have a longer survival time compared with COPD patients without AATD. ${ }^{4,5}$

Knowledge is limited on whether the prognosis after lung transplantation differs in oxygen-dependent patients with regard to their AATD status. ${ }^{5}$ Ringbaek et $\mathrm{al}^{5}$ reported that patients on LTOT with AATD ( $\mathrm{n}=234)$ were younger, had fewer comorbid diagnoses, were more likely to have undergone lung transplantation, and had a longer overall survival time compared with patients without AATD.

Sweden offers the unique opportunity to study survival with LTOT in relation to severe AATD by cross-linkage between the national prospective registries of LTOT and AATD with national data on vital status with near-complete follow-up.

The aim of the current study was to evaluate whether overall survival after lung transplantation differs between the oxygen-dependent COPD patients with severe AATD compared with those without.

\section{Patients and methods Study design and population}

This was a prospective, population-based, consecutive cohort study of patients on LTOT due to COPD between January 1, 1987, and June 30, 2015, in the Swedish National Registry for Respiratory Failure (Swedevox). Swedevox covers approximately $85 \%$ of all adults on LTOT in Sweden since January 1,1987 , as detailed elsewhere. ${ }^{6}$ The Swedish indications for LTOT are in line with international guidelines. ${ }^{7-9}$ We excluded patients who had undergone lung transplantation before starting LTOT.

\section{Data collection}

Data were obtained from Swedevox on age, sex, smoking status (never, former, or active smoking), physician-diagnosed disease that was the main reason for initiating LTOT, body mass index (BMI), blood gases, and the World Health Organization (WHO) performance status (a 5-point scale between 0 "fully active" and 4 "completely bedridden") ${ }^{10}$ at the initiation of LTOT (baseline).

AATD was defined as the presence of the PiZZ phenotype, confirmed by isoelectric focusing at the Department of Clinical Chemistry (DCC), Malmö, which is the central laboratory for all Pi phenotyping in Sweden since 1980. The results for all individuals with the PiZZ phenotype are stored and provided to the Swedish AATD registry that was started in $1991 .^{11}$
Data on lung transplantations were obtained from the two centers that perform all lung transplantations in Sweden, located at the university hospitals in Lund and Gothenburg as previously described. ${ }^{4,12}$

Data on comorbidities and hospitalizations during the 5 years prior to the initiation of LTOT were obtained from the Swedish National Patient Register (SNPR) and the National Cancer Registry. The SNPR covers more than $99 \%$ of all hospitalizations since 1987 and about $80 \%$ of all hospitalbased outpatient care since 2001 nationwide. ${ }^{13}$ Diagnoses were coded according to the 9th (before 1996) and the 10th revisions of the WHO International Classification of Disease (ICD). ICD codes were grouped (ICD-9; ICD-10) as cardiovascular disease (CVD; 390-459×; I00-I99), ischemic heart disease (410-414; I20-I25), heart failure (425, 428; I42, I50, I51.7), cerebrovascular diseases (430-438; I60-I69), venous thromboembolism $(415,451$; I26, I80), digestive organ diseases (520-579×, 787; K00-K93), lung cancer (162; C34), and other cancers (140-239×; C00-D48). Vital status was obtained from the National Causes of Death Register. Registers were cross-linked using Swedish system of personal identity numbers.

\section{Ethical considerations}

The study was approved by the research ethics committee of Lund University (157/2007, 350/2008, 2014/427, and 2015/186). According to Swedish research regulations for registry-based research, individual patient consent was not required.

\section{Statistical methods}

Baseline data were tabulated using frequencies and percentages for categorical variables, mean with SD, and median with range or interquartile range (IQR) for continuous variables with normal and skewed distribution, respectively. Continuous variables with normal distribution were compared using ANOVA.

Cumulative crude survival probabilities were estimated using the Kaplan-Meier method. Differences in crude survival were calculated using the log-rank test. The 1-, 3-, 5 -year survival rates were calculated using life tables. The association between AATD status and adjusted survival was analyzed using multivariable Cox regression and was expressed as hazard ratio (HR) with 95\% CI. For the analysis of survival of patients on LTOT, all participants were prospectively followed from the initiation of LTOT to the first of the following events, LTOT withdrawal, lung transplantation, death, or study end (June 30, 2015). The model was 
adjusted for baseline age, sex, smoking status, BMI ( $>20$ vs $\leq 20$ ), WHO performance status (2-4 vs $0-1)$, tension of arterial oxygen $\left(\mathrm{PaO}_{2}\right)$, and the presence of any of the following comorbidities during the 5 years before baseline: CVD, cancer, digestive disease, and diabetes. For survival after lung transplantation, the time period for the Cox analysis was from the date of transplantation to death or study end, and the model was adjusted for age at transplantation, sex, BMI, 1-min walk test (per $1 \mathrm{~m}$ ), type of lung transplant (single vs bilateral), time between LTOT start and LTx and comorbidities at baseline (CVD, digestive disease, and diabetes).

Statistical significance was defined as a two-sided $P$-value of $<0.05$. Statistical analyses were performed using the Statistical Package for the Social Sciences (SPSS) version 22.0 (IBM Corporation, Armonk, NY, USA).

\section{Results}

\section{Characteristics of participants}

Up to June 30, 2015, 14,658 patients who started LTOT

due to COPD were registered in Swedevox. After exclusion of patients who had undergone lung transplantation before starting LTOT ( $\mathrm{n}=14$; five with severe AATD), a total of 14,644 patients were included in the analysis. The median follow-up time was 1.6 (IQR, 2.7) years for the whole cohort and was significantly longer in AATD patients (2.4 years; IQR, 4.2) than in non-AATD patients (1.6 years; IQR, 2.7).

Characteristics of the study population by AATD status are provided in Table 1. Among the patients on LTOT, $1.9 \%$ had severe AATD. Compared with the COPD patients without AATD, the patients with severe AATD were younger, included a higher proportion of men and never smokers, and had a lower $\mathrm{FEV}_{1}$ (\% predicted). AATD patients also had a lower $\mathrm{PaCO}_{2}$ on both air and oxygen, with similar $\mathrm{PaO}_{2}$, resulting in a higher alveolar-arterial pressure gradient of oxygen $\left(\mathrm{P}_{\mathrm{A}-\mathrm{a}}\right)$.

Patients with severe AATD had less comorbidity at the time of starting LTOT, namely a lower prevalence of ischemic heart disease, heart failure, hypertension, cancer, depression, and diabetes mellitus (Table 2). A higher proportion of AATD patients underwent lung transplantation, $53(19 \%)$ vs $118(1 \%)$.

Table I Characteristics of 14,644 patients on LTOT for COPD

\begin{tabular}{|c|c|c|c|}
\hline Characteristics & All $(N=14,644)$ & AATD $(\mathbf{N}=\mathbf{2 8 4})$ & Non-AATD $(\mathrm{N}=14,360)$ \\
\hline Age & $73 \pm 9$ & $63 \pm 10 * *$ & $74 \pm 8$ \\
\hline Men & $6,409(44)$ & I54 (54) & $6,255(44)$ \\
\hline \multicolumn{4}{|l|}{ Smoking history } \\
\hline Never smokers & $686(5)$ & $57(20)$ & $626(4)$ \\
\hline Ex-smokers & 13,448 (92) & $227(80)$ & I3,222 (92) \\
\hline Missing & $510(3)$ & - & $512(4)$ \\
\hline $\mathrm{BMI}, \mathrm{kg} / \mathrm{m}^{2}$ & $23.6 \pm 6.1$ & $22.7 \pm 4.5$ & $23.6 \pm 6.1$ \\
\hline \multicolumn{4}{|l|}{ WHO performance status } \\
\hline $0-1$ & 6,807 (47) & $190(67)^{* *}$ & $6,617(46)$ \\
\hline $2-4$ & $6,634(45)$ & 7I $(25)^{* *}$ & $6,563(46)$ \\
\hline Missing & $\mathrm{I}, 203(8)$ & $23(8)$ & $\mathrm{I}, \mathrm{I} 80(8)$ \\
\hline $\mathrm{SpO}_{2}$ on air, $\%$ & $80 \pm 7.9$ & $84 \pm 3.5$ & $80 \pm 7.9$ \\
\hline $\mathrm{SpO}_{2}$ on oxygen, \% & $93 \pm 2.5$ & $95 \pm 0.8$ & $93 \pm 2.4$ \\
\hline $\mathrm{PaO}_{2}$ on air, $\mathrm{kPa}$ & $6.6 \pm 0.9$ & $6.8 \pm 0.8 * *$ & $6.6 \pm 0.9$ \\
\hline $\mathrm{PaCO}_{2}$ on air, $\mathrm{kPa}$ & $6.3 \pm 1.2$ & $5.4 \pm 1.0 * *$ & $6.3 \pm 1.2$ \\
\hline $\mathrm{P}_{\mathrm{A}-\mathrm{a}}, \mathrm{kPa}$ & $10.6 \pm 1.6$ & $1 \mathrm{I} .4 \pm 1.3^{*}$ & $10.5 \pm 1.6$ \\
\hline $\mathrm{PaO}_{2}$ on oxygen, $\mathrm{kPa}$ & $8.8 \pm 1.1$ & $9.0 \pm 0.9$ & $8.8 \pm I . I$ \\
\hline $\mathrm{PaCO}_{2}$ on oxygen, $\mathrm{kPa}$ & $6.5 \pm 1.3$ & $5.8 \pm 1.2$ & $6.6 \pm 1.2$ \\
\hline $\mathrm{FEV}_{1} / \mathrm{FVC}, \%$ & $46 \pm 23$ & $40 \pm 15^{* *}$ & $46 \pm 23$ \\
\hline $\mathrm{FEV}_{1}, \%$ of predicted & $36 \pm 19$ & $32 \pm 19 *$ & $36 \pm 19$ \\
\hline FVC, \% of predicted & $6 I \pm 23$ & $64 \pm 22$ & $61 \pm 23$ \\
\hline Prescribed oxygen flow, L/min & $1.6 \pm 1.0$ & $1.8 \pm 0.89$ & $1.6 \pm 1.0$ \\
\hline Prescribed oxygen duration, $h / 24 h$ & $18 \pm 3.5$ & $18 \pm 3.4$ & $18 \pm 3.5$ \\
\hline
\end{tabular}

Notes: Data are presented as mean \pm SD or frequency (\%) unless otherwise specified. The WHO performance status is a 5 -point scale $(0=$ fully active; $\mathrm{I}=$ symptomatic but completely ambulatory; $2=$ cannot work, ambulatory $>50 \%$ of the day; $3=$ capable of only limited self-care, ambulatory, $<50 \%$ of the day; and $4=$ completely disabled). $* P<0.01 ; * * P<0.001$.

Abbreviations: AATD, alpha-I antitrypsin deficiency; BMI, body mass index; FEV ${ }_{1}$, forced expiratory volume in I s; FVC, forced vital capacity; LTOT, long-term oxygen therapy; $\mathrm{P}_{\mathrm{A-a}}$, alveolar-arterial pressure gradient of oxygen; $\mathrm{PaCO}_{2}$, tension of arterial carbon dioxide; $\mathrm{PaO}_{2}$, tension of arterial oxygen; $\mathrm{SpO}_{2}$, saturation on pulse oximetry; WHO, World Health Organization. 
Table 2 Prevalence of comorbidities in patients on LTOT for COPD

\begin{tabular}{|c|c|c|c|c|}
\hline Comorbidity & All $(N=14,644)$ & AATD $(\mathbf{N}=284)$ & Non-AATD $(\mathrm{N}=\mid 4,360)$ & $P$-value \\
\hline All cancer & $719(5)$ & $8(3)$ & $711(5)$ & 0.06 \\
\hline Lung cancer & $266(2)$ & $2(1)$ & $264(2)$ & 0.20 \\
\hline All CVD & $7,437(5 \mathrm{I})$ & $96(34)$ & $7,34 I(5 I)$ & $<0.001$ \\
\hline Ischemic heart disease & $2,080(14)$ & $18(6)$ & $2,062(14)$ & $<0.001$ \\
\hline Heart failure & $2,854(20)$ & $24(9)$ & $2,830(20)$ & $<0.001$ \\
\hline Hypertension & $3,437(24)$ & $3 I(I I)$ & $3,406(24)$ & $<0.001$ \\
\hline Venous thromboembolism & $469(3)$ & $10(4)$ & $459(3)$ & 0.75 \\
\hline Cerebrovascular disease & $378(3)$ & $2(I)$ & $376(3)$ & 0.04 \\
\hline Depressive disorders & $\mathrm{I}, 809(\mathrm{I} 2)$ & $16(6)$ & $\mathrm{I}, 793(\mathrm{I})$ & $<0.00$ I \\
\hline Diabetes & $1,762(12)$ & $6(2)$ & $\mathrm{I}, 756(12)$ & $<0.001$ \\
\hline Gastrointestinal disease & $3,210(22)$ & $63(22)$ & $3,147(22)$ & 0.80 \\
\hline Liver disease & $296(2)$ & $9(3)$ & $287(2)$ & 0.20 \\
\hline
\end{tabular}

Note: Data presented as $n$ (\%).

Abbreviations: AATD, alpha-I antitrypsin deficiency; CVD, cardiovascular disease; LTOT, long-term oxygen therapy.

\section{Survival on LTOT}

There were 201 (71\%) deaths among the patients with AATD and $12,354(86 \%)$ deaths among the patients without AATD during LTOT. The median survival time was 1.9 years $(95 \%$ CI, 1.8-1.9) overall, and significantly longer in patients with AATD (3.5 years; $95 \%$ CI, 2.8 -4.3 ) than in patients without AATD (1.9 years; 95\% CI, 1.8-1.9; $P<0.001$; Figure 1). The 1-, 3-, and 5-year survival rates were $0.84(95 \% \mathrm{CI}$, $0.80-0.88), 0.55$ (95\% CI, 0.52-0.61), and 0.36 (95\% CI, $0.31-0.44)$ for patients with AATD compared with 0.67 (95\% CI, 0.67-0.68), 0.48 (95\% CI, 0.46-0.48), and 0.17 (95\% CI, $0.16-0.17)$ for patients without AATD, respectively.

In multivariate Cox regression, patients without AATD had an increased risk of all-cause mortality, HR 1.53 (95\% CI, 1.24-1.88; $P<0.001$ ), compared with patients with severe AATD (Table 3). Earlier death was also independently predicted by higher age, male sex, BMI, worse WHO performance

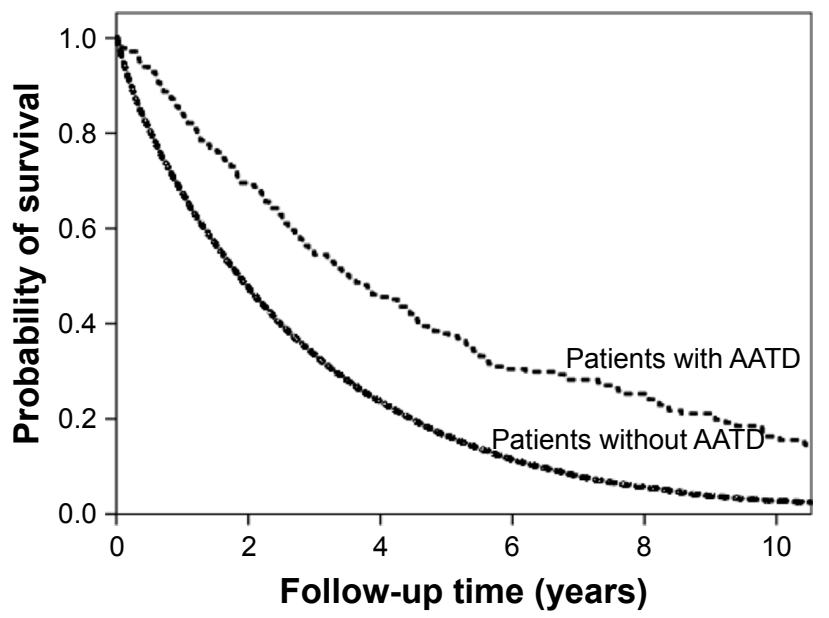

Figure I Survival in relation to the presence of severe AATD in patients on LTOT. Abbreviations: AATD, alpha-I antitrypsin deficiency; LTOT, long-term oxygen therapy. status, lower $\mathrm{PaO}_{2}$ (air), and the presence of CVD, cancer, digestive disease, or diabetes mellitus at the time of starting LTOT. Patients without AATD had more deaths from CVD (16\% vs $6 \%$; $P<0.001$; Table 4$)$.

\section{Survival after lung transplantation}

During the follow-up, 171 patients underwent LTx. Of these, 53 (31\%) had severe AATD. The median time from the start of LTOT to LTx was 1.5 (IQR, 2.1) years. Of the transplanted patients, $69 \%$ were women and $96 \%$ were ex-smokers (Table 5). During the follow-up of a median of 4.4 (IQR, 6) years after LTx, 103 patients died, of whom 36 (35\%) had severe AATD. The median survival time after LTx for all patients was 6.3 years (95\% CI, 4.2-8.3), with no significant difference between patients with severe AATD (7.2 years; 95\% CI, 3.1-11.3) and patients without AATD (6.1 years; 95\% CI, 3.6-8.4; $P=0.9$ ).

Table 3 Multivariate Cox regression of survival in COPD patients on LTOT

\begin{tabular}{|c|c|c|}
\hline Factor & HR (95\% CI) & P-value \\
\hline Non-AATD vs AATD & $1.53(1.24-1.88)$ & $<0.001$ \\
\hline Age (per I year) & $1.04(1.03-1.04)$ & $<0.001$ \\
\hline Men vs women & $1.28(1.22-1.34)$ & $<0.001$ \\
\hline Ever smokers vs never smokers & $0.96(0.86-1.07)$ & 0.52 \\
\hline $\mathrm{BMI} \leq 22$ vs $>22$ & $1.43(1.36-1.50)$ & $<0.001$ \\
\hline WHO performance status $2-4$ vs $0-I$ & $1.40(1.33-1.47)$ & $<0.001$ \\
\hline $\mathrm{PaO}_{2}$ on air $($ per I kPa) & $0.92(0.89-0.94)$ & $<0.001$ \\
\hline Cancer & $1.35(1.21-1.50)$ & $<0.001$ \\
\hline CVD & $1.09(1.04-1.15)$ & $<0.001$ \\
\hline Digestive disease & $1.12(1.10-1.18)$ & $<0.001$ \\
\hline Diabetes mellitus & $1.21(1.12-1.30)$ & $<0.001$ \\
\hline
\end{tabular}

Abbreviations: AATD, alpha-I antitrypsin deficiency; BMI, body mass index; CVD, cardiovascular disease; HR, hazard ratio; LTOT, long-term oxygen therapy; $\mathrm{PaO}_{2}$, tension of arterial oxygen; WHO, World Health Organization. 
Table 4 Underlying cause of death in 12,555 patients with oxygen-dependent COPD

\begin{tabular}{lllll}
\hline Cause of death & All patients (N=I2,555) & Patients with AATD (N=20I) & Patients without AATD (N=I 2,354) & P-value \\
\hline Respiratory & $8,558(68)$ & $155(77)$ & $8,403(68)$ & 0.65 \\
Cardiovascular & $2,015(16)$ & $12(6)$ & $2,003(16)$ & $<0.001$ \\
Cancer & $879(7)$ & $17(9)$ & $862(7)$ & 0.57 \\
Gastrointestinal & $165(\mathrm{I})$ & $6(3)$ & $159(\mathrm{I})$ & 0.70 \\
Infection & $142(\mathrm{I})$ & $4(2)$ & $138(\mathrm{I})$ & 0.86 \\
Others & $796(7)$ & $7(3)^{*}$ & $789(7)$ & $<0.00 \mathrm{I}$ \\
\hline
\end{tabular}

Notes: Data are presented as frequency (\%) of deaths. *Renal failure, accidents, and connective tissue disease.

Abbreviation: AATD, alpha-I antitrypsin deficiency.

The risk of death was not increased in the AATD patients compared with the non-AATD patients, HR 0.98 (95\% CI, $0.60-1.60 ; P=0.61)$, after adjustment for age at transplantation, sex, BMI, 6-min walk test, single LTx vs bilateral LTx, time between LTOT start and LTx, and comorbidity (CVD, digestive disease, cancer, diabetes). The only statistically significant predictor of earlier death after LTx was higher age (Table 6).

\section{Discussion}

\section{Main findings}

Of the patients with oxygen-dependent COPD, $1.9 \%$ had severe AATD. Patients with AATD were younger, had less comorbidity, and were more likely to undergo lung transplantation compared with those without AATD. Patients with severe AATD had a lower mortality rate during LTOT, especially death due to CVDs, but a similar prognosis after lung transplantation.

Table 5 Demographic data of COPD patients on LTOT who underwent lung transplantation

\begin{tabular}{|c|c|c|c|}
\hline Characteristic & $\begin{array}{l}\text { All } \\
(N=|7|)\end{array}$ & $\begin{array}{l}\text { With AATD } \\
(\mathrm{N}=53)\end{array}$ & $\begin{array}{l}\text { Without AATD } \\
(\mathrm{N}=1 / 8)\end{array}$ \\
\hline Men, n (\%) & $53(3 I)$ & $27(5 \mathrm{I})$ & $26(22)$ \\
\hline Age at transplantation & $57 \pm 7$ & $56 \pm 7$ & $57 \pm 7$ \\
\hline Never smokers & $7(4)$ & $I(2)$ & $6(5)$ \\
\hline Ever smokers & $164(96)$ & $52(98)$ & $112(95)$ \\
\hline Pack-years & $27 \pm 15$ & $22 \pm 11 * *$ & $29 \pm 16$ \\
\hline Single LTx & $107(63)$ & $34(64)$ & $73(62)$ \\
\hline $\mathrm{BMI}, \mathrm{kg} / \mathrm{m}^{2}$ & $22 \pm 4$ & $22 \pm 4$ & $22 \pm 4$ \\
\hline Six-min walk test (per I m) & $188 \pm 94$ & $160 \pm 78 *$ & $202 \pm 98$ \\
\hline $\mathrm{FEV}_{1}, \%$ of predicted & $22 \pm 8$ & $22 \pm 9$ & $23 \pm 7$ \\
\hline \multicolumn{4}{|l|}{ Comorbidity } \\
\hline CVD & $57(33)$ & $17(32)$ & $40(34)$ \\
\hline Digestive disease & $31(18)$ & $10(19)$ & $21(18)$ \\
\hline Diabetes mellitus & $7(4)$ & $4(8)$ & $3(3)$ \\
\hline
\end{tabular}

Notes: Data are presented as mean \pm SD or frequency (\%). $* P<0.05$, $* * P<0.01$ (missing values in 50 patients).

Abbreviations: AATD, alpha-I antitrypsin deficiency; BMI, body mass index; CVD, cardiovascular disease; $\mathrm{FEV}_{\text {, }}$, forced expiratory volume in I s; LTx, lung transplantation; LTOT, long-term oxygen therapy.

\section{What this study adds?}

These findings confirm those of Ringbaek et $\mathrm{al}^{5}$ that patients with AATD were younger and had fewer comorbidities (CVD and diabetes mellitus), a higher rate of LTx, and a longer survival compared with other COPD patients on LTOT. In addition, in the current study, AATD patients also had lower $\mathrm{FEV}_{1} \%$ predicted and less diagnosed depression. ${ }^{5}$ The prevalence of AATD in patients on LTOT for COPD was somewhat higher in the current study compared with that reported in the study by Ringbaek et $\mathrm{al}^{5}(1.9 \%$ vs $1.1 \%$ ), as severe AATD was identified using national data on all known PiZZ phenotypes from the laboratory performing all tests in Sweden. The prevalence is similar to the estimated prevalence of AATD across all stages of COPD. ${ }^{1}$

In comparison with the non-AATD patients, we found that AATD patients had lower $\mathrm{PaCO}_{2}$ on both air and oxygen but similar $\mathrm{PaO}_{2}$, resulting in an increased $\mathrm{P}_{\mathrm{A}-\mathrm{a}}$ oxygen gradient. This finding indicates that AATD patients have more impaired diffusion capacity than the non-AATD patients, possibly because of more severe emphysema. This complements the findings of the Long-Term Oxygen Therapy Trial (LOTT) that patients with AATD $(n=11)$ desaturated

Table 6 Multivariate Cox regression of mortality after lung transplantation in patients on LTOT

\begin{tabular}{lll}
\hline Factor & HR $(95 \%$ CI) & P-value \\
\hline Non-AATD vs AATD & $0.98(0.60-1.60)$ & $0.6 I$ \\
Age at transplantation (per I year) & $1.05(1.01-1.09)$ & 0.009 \\
Men vs women & $0.93(0.56-1.54)$ & 0.33 \\
BMI (per I kg/m²) & $0.96(0.9 I-1.02)$ & 0.21 \\
Six-min walk distance (per I m) & $0.99(0.99-1.01)$ & 0.39 \\
Single vs bilateral LTx & $0.90(0.48-1.70)$ & 0.74 \\
Time between LTOT start and LTx & $0.96(0.84-1.01)$ & 0.70 \\
(per I year) & & \\
Comorbidity* & $1.02(0.62-1.70)$ & 0.94 \\
\hline
\end{tabular}

Note: *Comorbidity was defined as the presence of cancer, CVD, depression, digestive disease, diabetes mellitus, or gastrointestinal disease.

Abbreviations: AATD, alpha-I antitrypsin deficiency; BMI, body mass index; CVD, cardiovascular disease; HR, hazard ratio; LTx, lung transplantation; LTOT, long-term oxygen therapy. 
more during a walking test, which is likely to be related to a more impaired diffusion capacity. ${ }^{14}$

The current study provides novel data on survival after LTx in relation to PiZZ status as well as sex in oxygendependent COPD. Most studies to date have reported a $20 \%-40 \%$ higher mortality rate in men than in women on LTOT, but the reasons are unknown. ${ }^{15}$ The sex difference in mortality in the current analysis $(28 \%$ higher in men than in women) was attenuated and became nonsignificant after LTx. One explanation could be that comorbidities are contraindications for LTx, suggesting that comorbidities are an important contributing factor to the sex difference in survival on LTOT.

\section{Mechanism}

Patients with AATD, due to their higher susceptibility to develop lung impairment, are younger and have smoked less when they develop hypoxemic COPD compared with patients without AATD. Along the same line, they have fewer diagnosed and silent comorbidities, and thus more AATD patients are eligible for LTx and their survival is longer on LTOT. However, in contrast to our previously published report, ${ }^{4}$ we did not find any significant difference in survival after LTx between the AATD and the non-AATD patients. This may be explained by the fact that the analysis included only patients on LTOT and that the number of patients was lower, reducing the statistical power of the analyses.

Alpha-1 antitrypsin augmentation therapy is not generally recommended in Sweden. Since 2007, the treatment is licensed in Sweden, but it is not reimbursed by the health care system.

\section{Strengths and limitations}

The strengths of the current study include the fact that it was population based, covering $85 \%-90 \%$ of all patients on LTOT in Sweden, with prospective follow-up of all lung transplantations and deaths nationwide. No patient was lost to follow up. The PiZZ phenotype in all AATD patients was confirmed by isoelectric focusing.

Limitations are that only smoking status and no data on cumulative smoking exposure were available for the nonAATD patients, except for those patients who had undergone lung transplantation. Pi phenotyping was available in all AATD patients but not in all non-AATD patients. However, the high prevalence of the PiZZ phenotype among the study population (1.9\%) indicated that AAT has been analyzed in most patients with LTOT in Sweden.

\section{Implications}

For the clinician, AATD status may be an aid in determining a patient's prognosis. Similar survival after LTx irrespective of the presence of AATD supports appropriate evaluation and selection of patients to be transplanted in oxygen-dependent COPD. Moreover, these data suggest that chest physician should be more observant of desaturation in patients with severe AATD. Regular follow-up of saturation and blood gases to detect the development of chronic hypoxemia is advisable. Further studies are needed on the effect of AATD on quality of life, exacerbation, and survival with more details on physiological data including diffusing capacity and exercise test.

\section{Conclusion}

In oxygen-dependent COPD, patients with severe AATD have a longer survival time but a similar prognosis after lung transplantation compared with non-AATD patients.

\section{Acknowledgments}

We thank Associate Professors Kerstin Ström and Eeva Piitulainen, founders of the Swedevox and AATD registers, for being a constant source of inspiration. We also thank all the Swedish physicians and nurses who report data to these registers. ME was supported by unrestricted grants from the Swedish Society of Medicine and the Swedish Heart-Lung Foundation, and HT was supported by unrestricted grants from the Skåne University Hospital and the Swedish HeartLung Foundation.

\section{Disclosure}

The authors report no conflicts of interest in this work.

\section{References}

1. Luisetti M, Seersholm N. $\alpha(1)$-antitrypsin deficiency 1: epidemiology of $\alpha(1)$-antitrypsin deficiency. Thorax. 2004;59(2):164-169.

2. Vogelmeier CF, Criner GJ, Martinez FJ, et al. Global strategy for the diagnosis, management, and prevention of chronic obstructive lung disease 2017 report. GOLD Executive Summary. Am J Respir Crit Care Med. 2017;195(5):557-582.

3. Tanash H, Ekström M, Lindberg A, Rönmark E, Piitulainen E. Survival in individuals with severe alpha 1-antitrypsin deficiency (PiZZ) in comparison with a general population with known smoking habits. Eur Respir J. 2017;50(3):pii: 1700198

4. Tanash HA, Riise GC, Ekstrom MP, Hansson L, Piitulainen E. Survival benefit of lung transplantation for chronic obstructive pulmonary disease in Sweden. Ann Thorac Surg. 2014;98(6):1930-1935.

5. Ringbaek TJ, Seersholm N, Perch M, Iversen M, Lange P. Prognosis of patients with alpha1-antitrypsine deficiency on long-term oxygen therapy. Respir Med. 2014;108(8):1189-1194.

6. Gustafson T, Löfdahl K, Ström K. A model of quality assessment in patients on long-term oxygen therapy. Respir Med. 2009;103(2):209-215. 
7. Hardinge M, Annandale J, Bourne S, et al. British Thoracic Society guidelines for home oxygen use in adults. Thorax. 2015;70(suppl 1): i1-i43.

8. Medical Research Council Working Party. Long term domiciliary oxygen therapy in chronic hypoxic cor pulmonale complicating chronic bronchitis and emphysema. Lancet. 1981;1(8222):681-686.

9. Nocturnal Oxygen Therapy Trial Group. Continuous or nocturnal oxygen therapy in hypoxemic chronic obstructive lung disease: a clinical trial. Ann Intern Med. 1980;93(3):391-398.

10. Oken MM, Creech RH, Tormey DC, et al. Toxicity and response criteria of the Eastern Cooperative Oncology Group. Am JClin Oncol. 1982;5(6): 649-655.

11. Piitulainen E, Tanash HA. The clinical profile of subjects included in the Swedish National Register on individuals with severe alpha 1-antitrypsin deficiency. COPD. 2015;12(suppl 1):36-41.
12. Tanash HA, Riise GC, Hansson L, Nilsson PM, Piitulainen E. Survival benefit of lung transplantation in individuals with severe alpha1-anti-trypsin deficiency (PiZZ) and emphysema. J Heart Lung Transplant. 2011;30(12):1342-1347.

13. Ludvigsson JF, Andersson E, Ekbom A, et al. External review and validation of the Swedish national inpatient register. BMC Public Health. 2011;11:450.

14. Stoller JK, Aboussouan LS, Kanner RE, et al; LOTT Research Group. Characteristics of alpha-1 antitrypsin-deficient individuals in the longterm oxygen treatment trial and comparison with other subjects with chronic obstructive pulmonary disease. Ann Am Thorac Soc. 2015; 12(12):1796-1804.

15. Ekstrom MP, Jogreus C, Strom KE. Comorbidity and sex-related differences in mortality in oxygen-dependent chronic obstructive pulmonary disease. PLoS One. 2012;7(4):e35806.

\section{Publish your work in this journal}

The International Journal of COPD is an international, peer-reviewed journal of therapeutics and pharmacology focusing on concise rapid reporting of clinical studies and reviews in COPD. Special focus is given to the pathophysiological processes underlying the disease, intervention programs, patient focused education, and self management protocols.

\section{Dovepress}

This journal is indexed on PubMed Central, MedLine and CAS. The manuscript management system is completely online and includes a very quick and fair peer-review system, which is all easy to use. Visit http://www.dovepress.com/testimonials.php to read real quotes from published authors.

Submit your manuscript here: http://www.dovepress.com/international-journal-of-chronic-obstructive-pulmonary-disease-journal 